\title{
Fuzzy cognitive modeling of product import and export impacts on food security
}

\author{
A.F. Rogachev ${ }^{1,2, *}$, and E.V. Melikhova ${ }^{2}$ \\ ${ }^{1}$ All-Russian research Institute of irrigated agriculture, Volgograd, Russian Federation \\ ${ }^{2}$ Volgograd State Agrarian University, Volgograd, Russian Federation
}

\begin{abstract}
The modern economy of the Russian Federation is in a difficult foreign economic situation, due to the sanctions pressure forced import substitution in a number of sectors of agricultural production. The sanctions imposed by developed countries led to a response from Russia, which imposed an embargo on certain groups of agricultural raw materials and food products. The aim of the research is to develop and implement software for fuzzy cognitive modeling of the level of food security in the context of import substitution, taking into account food exports. To determine the perspective directions of numerical estimation and increase the level of FS in modern Russia, by modeling and justifying import substitution, the method of fuzzy cognitive mathematical modeling is used, which allows us to build models of the evolution of the emerging level of interaction of key factors of the simulated system. The conducted cognitive modeling of the FS level showed that import substitution increases infrastructure costs and has a positive effect on the overall economic situation, as it determines the development of production. The study of the mutual influence of the import substitution factor, within the framework of ensuring the required level of FS, is limited by the existing conditions, largely determined by the sanctions pressure on the Russian Federation. It is shown that a promising area of research is the analysis of the sensitivity of the cognitive model to the influence of all key factors, as well as the search for factors that are most responsive to the control actions of the governing bodies.
\end{abstract}

\section{Introduction}

The Russian economy is currently in a difficult geopolitical foreign economic situation, largely due to the forced import substitution in a number of sectors of agricultural production, due to sanctions pressure. In such conditions, the issue of economic security and self-sufficiency in food products becomes particularly relevant.

The sanctions imposed by developed countries that began in 2014 led to a forced response from Russia, which imposed an embargo on certain groups of agricultural raw materials and food products. Financial and trade sanctions imposed on Russia have led to negative economic consequences, including threats to food security (FS). The solution to this problem is a prerequisite for Russia to preserve its food sovereignty (Antamoshkina E.

* Corresponding author: rafr@mail.ru 
et al., 2019). At the same time, the development and implementation of the state agri-food policy, including the methodology for assessing and predicting the FS level, determines the relevance of research in this area.

Monographic analysis of research in the field of FS allowed us to identify theoretical and applied areas, including system mathematical modeling. The latter is focused on the model description of various aspects of ensuring FS, including identification and analysis of the causes of food security threats, identification of key groups of factors and promising ways to solve the problem, which is reflected in numerous publications (Bannikova et al., 2015), (Jacknowitz et al., 2015), (Mazaeva and Rogachev, 2012), (Medernakh and Burnod, 2013), (Popkova et al., 2015a), (Popkova et al., 2015b), (Popova et al., 2015), etc.

The authors of this article believe that, in the context of foreign countries, promising tools for solving the FS problem and eliminating identified threats are described in (Bernardes, 2015), (Garthwaite et al., 2015), (Grouiez, 2012), (He, 2015), (Maitra and Rao, 2015), and others.

At the same time, the specifics of providing FS in the conditions of modern Russia, the number of works devoted to its features is relatively small, which necessitates further research in this area.

The aim of the research is to develop and implement a software methodology for fuzzy cognitive modeling of the level of food security, taking into account food exports in the context of import substitution. At the same time, to build fuzzy cognitive models (FCM), it is necessary to take into account such key factors as agricultural production, consumption, and management of necessary stocks when modeling (Borisov V, Luferov V, 2020; Podvesovskii A. et al., 2019; Belskaya S. V. et al., 2019; Zagranovskaya A., 2018). Forecasting the FS level, which is possible on the basis of such modeling, will contribute to the development and adjustment of a science-based import substitution strategy in the modern Russian economy.

\section{Methods}

The research uses fundamental methods of system analysis - comparative and cognitive analysis, the theory of algorithms, and the theory of multidimensional time series.

To determine promising areas for numerical evaluation and increase the level of FS in modern Russia, by modeling and justifying import substitution, the authors use the method of cognitive mathematical modeling, which allows us to build models of the evolution of the emerging level of mutual influence of key factors. This allows you to predict and manage its changes in the process of implementing the import substitution strategy.

In the process of constructing and identifying fuzzy cognitive models, the following stages were distinguished: structural identification-definition of a set of concepts and a clear relationship over this set; parametric identification, including the transition from a clear to a fuzzy relationship with expert determination of the intensity of influence between factors. Graphically, FCM can be represented as a directed weighted graph whose vertices correspond to elements of the modeled set, and whose arcs correspond to non-zero elements of the relation $W$ between concepts. The ratio $W$ can be represented as a matrix of dimension $n \times n$ (where $n$ - is the number of factors), which can be considered as the adjacency matrix of the graph.

To describe the FS support system based on domain analysis, FCM was constructed in the form of a weighted directed graph, the structure and parameters of which were set by the adjacency matrix $A\left(\mathrm{a}_{\mathrm{ij}}\right)[8,14]$.

Computer implementation of cognitive modeling was carried out using the Strategist computer system developed at the Volgograd State Technical University [13]. This system 
has a user-friendly interface that provides interactive construction, visualization and research of a fuzzy cognitive model.

To substantiate the composition of the key concepts of the simulated system in the framework of computer support for modeling and correcting the mutual influence between the concepts, the method of recurrent addition FCM was used.

\section{Results}

The analysis of publications confirmed that import substitution plays an important role in ensuring the FS and the economy of modern Russia. Since the natural and climatic conditions of agricultural production in Russia are not always favorable, and the economic conditions of doing business are complicated by high inflation, unstable political situation and legislation in the field of taxation, as well as high corruption (Popova L. et al., 2016), food production in Russia is impossible without significant support from the state.

To improve the described situation with the provision of FS, effective import substitution is necessary, based on active state support and the creation of favorable conditions for the development of domestic food production (Skiter et al., 2015b).

To build an FCM that simulates the agri-food situation on the example of the Volgograd region, statistical data obtained from official sources of state statistics were previously analyzed (Fig. 1, 2).

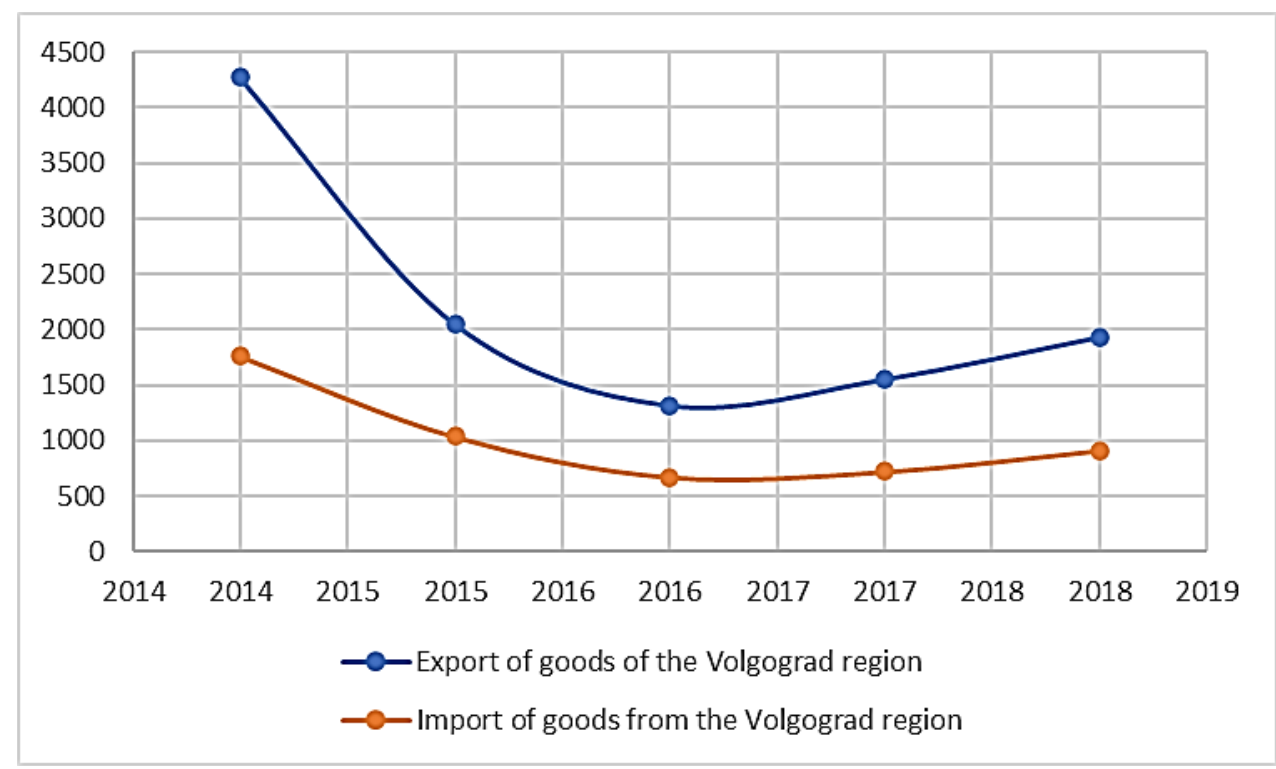

Fig. 1. Import and export of goods in the Volgograd region, \$ million

Analysis of the diagrams in figure 1 shows the predominance of regional exports over imports, as well as changes in the dynamics of these indicators in 2016-2017.

The state strategy of import substitution assumes that investments in the development of domestic food production are long-term. At the same time, the initial expenditures of the state budget can be returned by increasing tax revenues from exporters and agri-food organizations, which can become competitive in the domestic and foreign markets (Skiter et al., 2015a).

The situation is similar for the group of agricultural raw materials and food products (Fig. 2). 


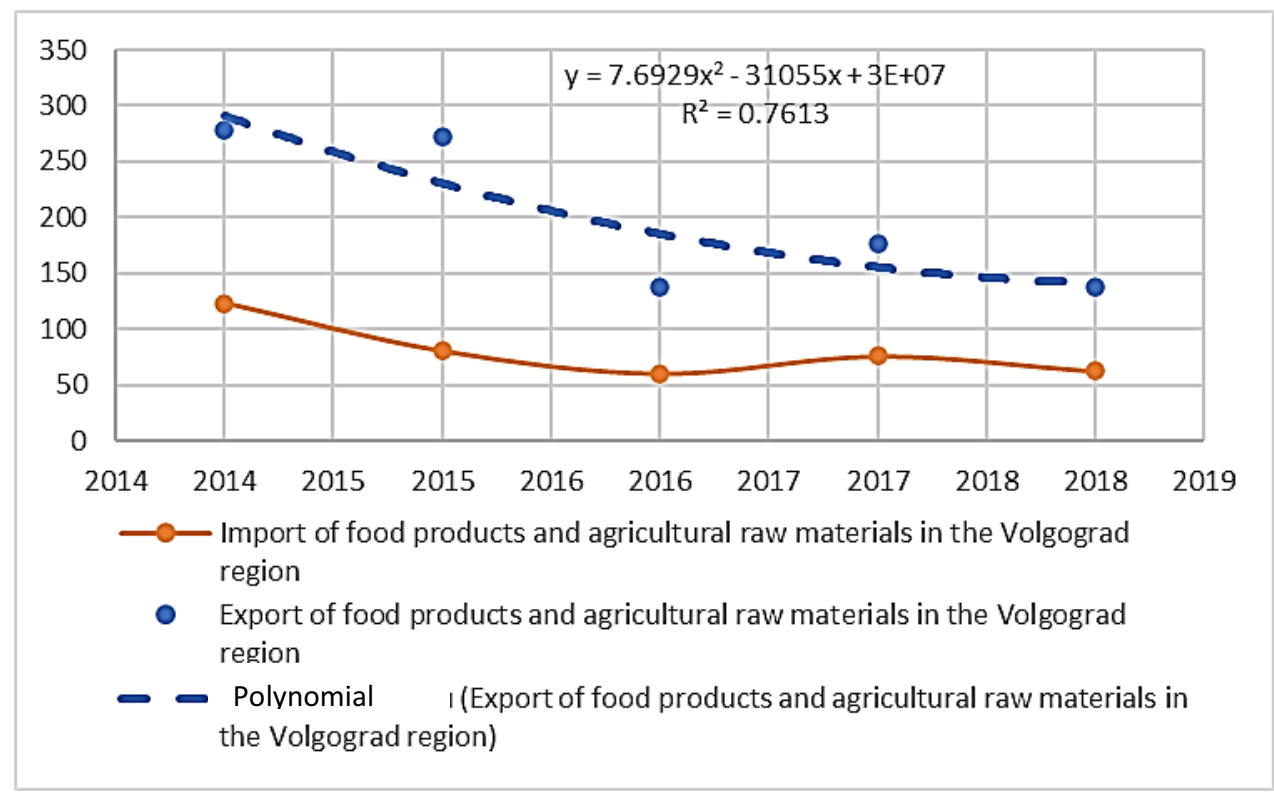

Fig. 2. Import and export of agricultural raw materials and food products in the Volgograd region, $\$$ million

Analysis of the diagrams in figure 2 also shows the predominance of regional food exports over imports. In addition, the change in the dynamics of these indicators, in contrast to the previous generalized group, over the entire analyzed period is characterized by a monotonous reduction. At the same time, the reduction in exports, adequately $\left(\mathrm{R}^{2}=0.7613\right)$ described by the parabolic dependence (1), occurs at a higher rate

$$
y=7.693 \cdot t^{2}-31055 \cdot t+3 \mathrm{E} 07
$$

where

$\boldsymbol{y}$ - is the export of agricultural raw materials and food products in, \$ million;

$t$ - is years.

These factors of ensuring FS through import substitution should be taken into account in cognitive modeling.

Thus, the cognitive model should qualitatively show a similar picture of the evolution of the agri-food system that provides the FS of the region. The fuzzy cognitive model included the following factors (Table 1).

The relationship of the 10 concepts listed, including "Import" of food products. the FCM is shown in Fig. 3. Diagrams of the evolution of indicators of the agri-food system are shown in Fig. 4

Table 1. Factors of the developed fuzzy cognitive model

\begin{tabular}{|l|l|l|}
\hline \multicolumn{1}{|c|}{$\begin{array}{c}\text { The enlarged } \\
\text { group }\end{array}$} & \multicolumn{1}{|c|}{ Name of the concept } & \multicolumn{1}{c|}{ Note } \\
\hline $\begin{array}{l}\text { Production and } \\
\text { processing of } \\
\text { products }\end{array}$ & Production and processing of meat products & \\
\cline { 3 - 4 } Consumption & Production and processing of crop products & $\begin{array}{l}\text { Including vegetables and } \\
\text { fruits }\end{array}$ \\
\hline Stocks food & Consumption of food products & $\begin{array}{l}\text { Including vegetables and } \\
\text { fruits }\end{array}$ \\
\hline
\end{tabular}


Table 1. Continued

\begin{tabular}{|l|l|l|}
\hline Import & Import of food products & Including seeds \\
\hline Exports & Export of food products, & Mainly grain products \\
\hline $\begin{array}{l}\text { Economic } \\
\text { infrastructure }\end{array}$ & $\begin{array}{l}\text { State of the economy and budget support for } \\
\text { rural producers }\end{array}$ & $\begin{array}{l}\text { Development of land reclamation and } \\
\text { increase of fertility }\end{array}$ \\
\hline Ecology & $\begin{array}{l}\text { Ecological state of the environment and the } \\
\text { products consumed }\end{array}$ & $\begin{array}{l}\text { Including the productivity } \\
\text { of fields }\end{array}$ \\
\hline Level FS & Integral level FS & $\begin{array}{l}\text { Dimensionless numerical } \\
\text { indicator }\end{array}$ \\
\hline
\end{tabular}

Note the presence of both one-way relationships, such as the negative impact of "Production and processing - Ecology", and two-way"Economy - reserves" (positive), "Reserves-economy" (negative)".

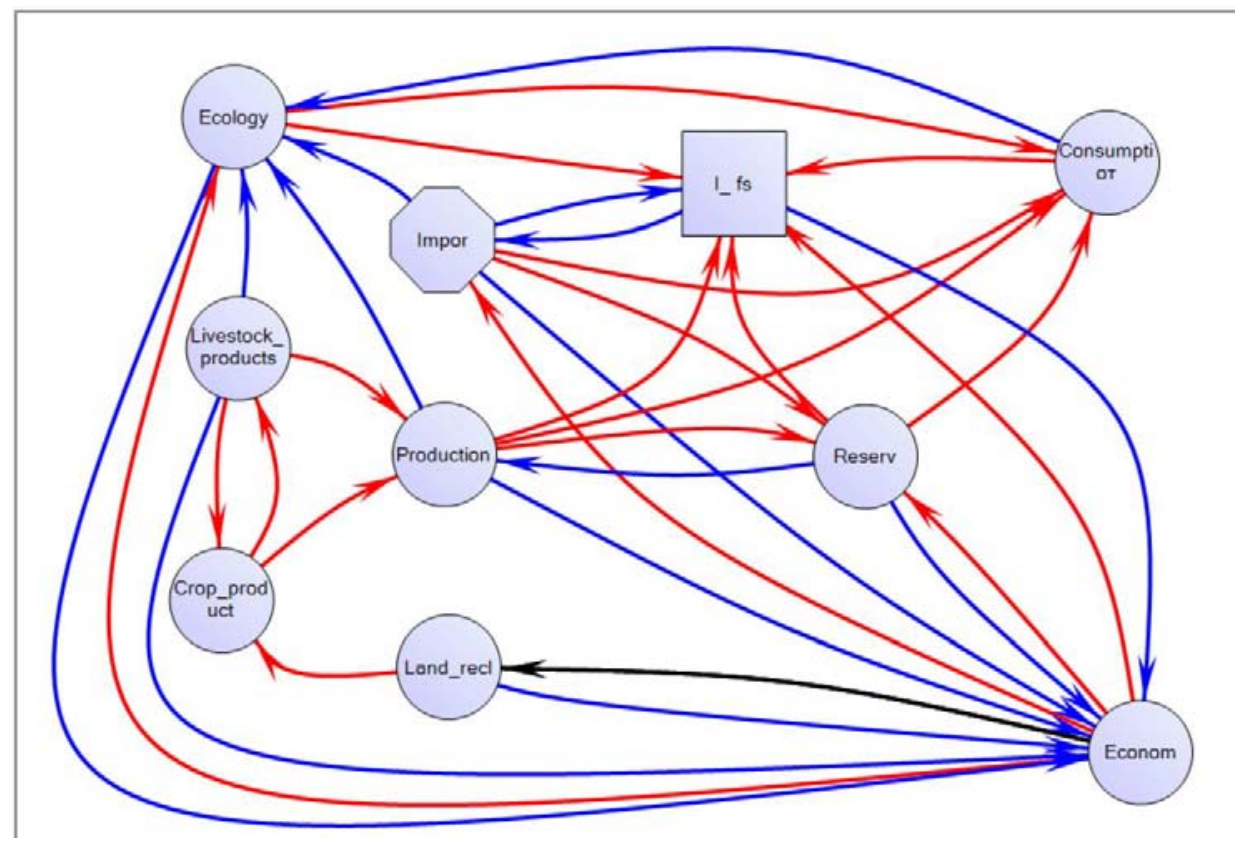

Fig. 3. Relationship of FCM concepts without food exports

Analysis of the diagrams in Fig. 4 allows, despite the fluctuating nature of their changes during the transition period, to distinguish groups of increasing ("FS Level", "Production", "Crop production"), stagnating ("Consumption") and falling indicators ("Import", "Land reclamation”, "Economy”, "Ecology”). 

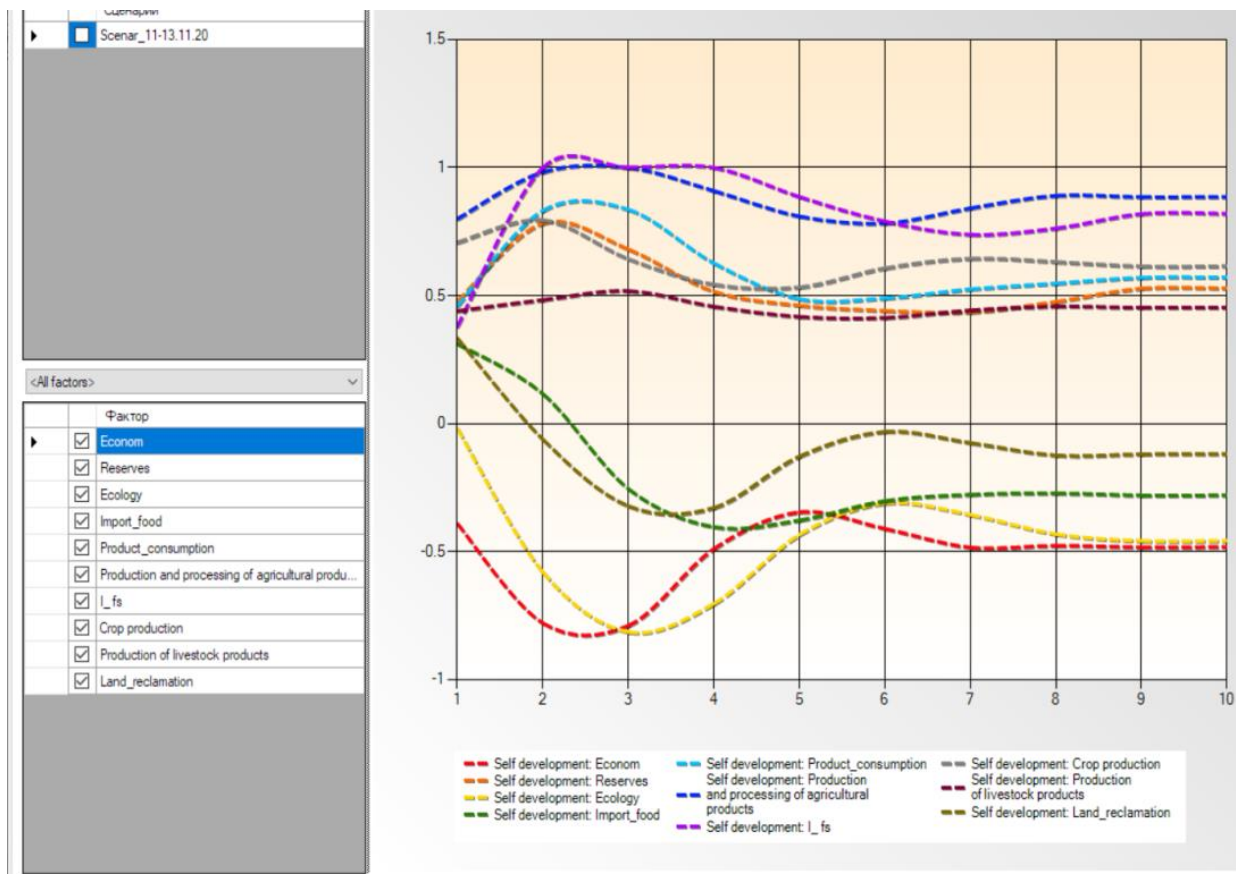

Fig. 4. Diagrams of the evolution of indicators of the regional agri-food system

Since the region under study is characterized by a predominance of exports over imports, we will analyze the impact of the concept of "Export" (Fig. 5).

The introduction of export impact accounting in FCM required adding the following links to the concept of "Export»:

- $\quad$ "Production and processing", The power of influence -0.2 ;

- $\quad$ "Reserves", Thepower of influence -0.26;

- "Economy", "The power of influence +0.20 .

- Influence of other concepts on" Export " is characterized by:

- $\quad$ "Crop production", "The power of influence +0.22 .

Change in the evolution of indicators of such a system is presented below.

With model values of parameters, the introduction of the concept "Export of food products" leads to some improvement in the level of indicators " Economy "and, accordingly, directly dependent on it"Irrigation reclamation". 


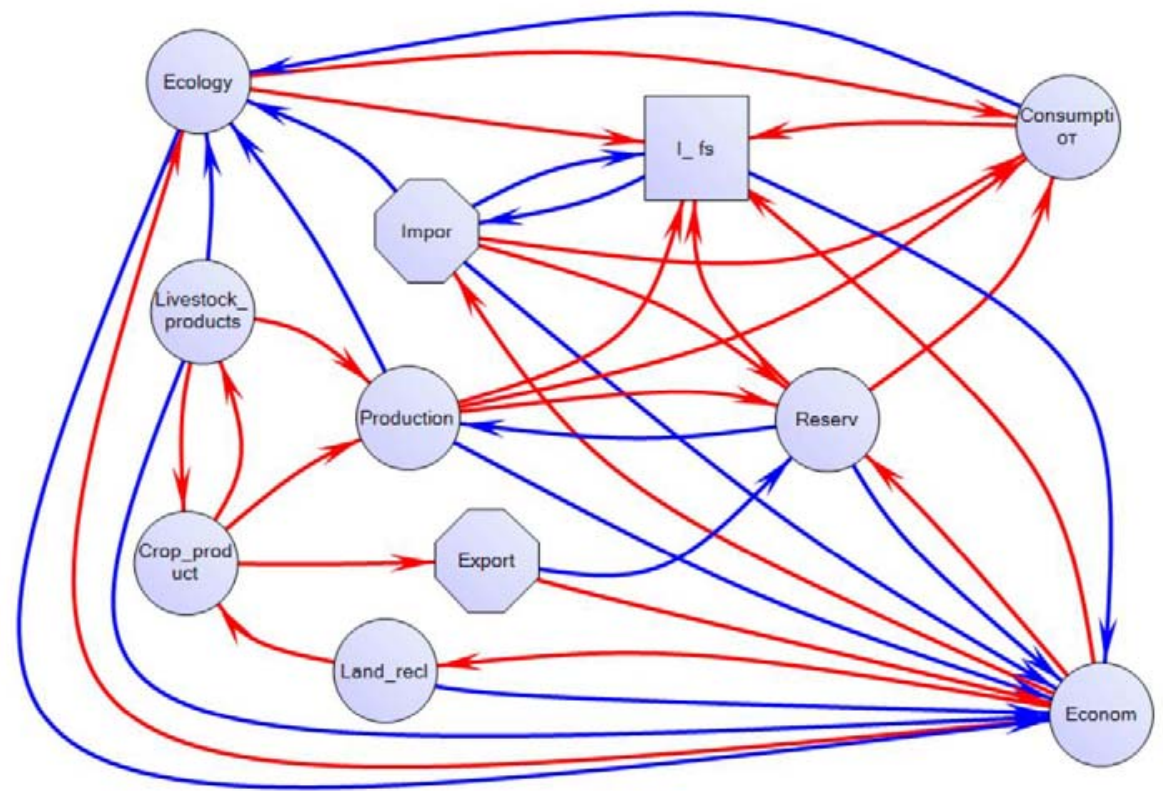

Fig. 5. Relationship between FCM concepts and food exports

Other indicators, as well as the nature of their evolution, have not changed much.
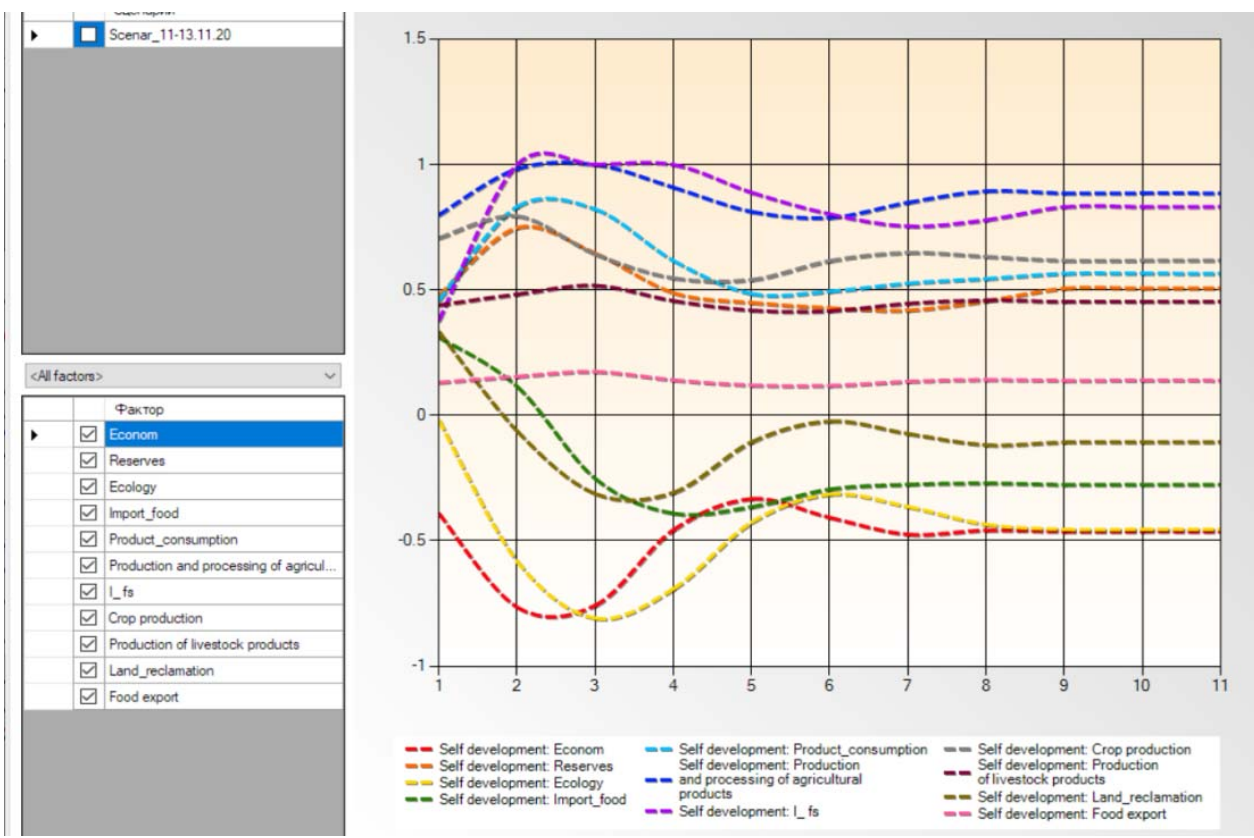

Fig. 6. Dynamics of the simulated evolution of FCM indicators taking into account food exports

To clarify the impact of the "Import" concept, let's compare the dynamics of changes in all indicators (Fig. 7). 


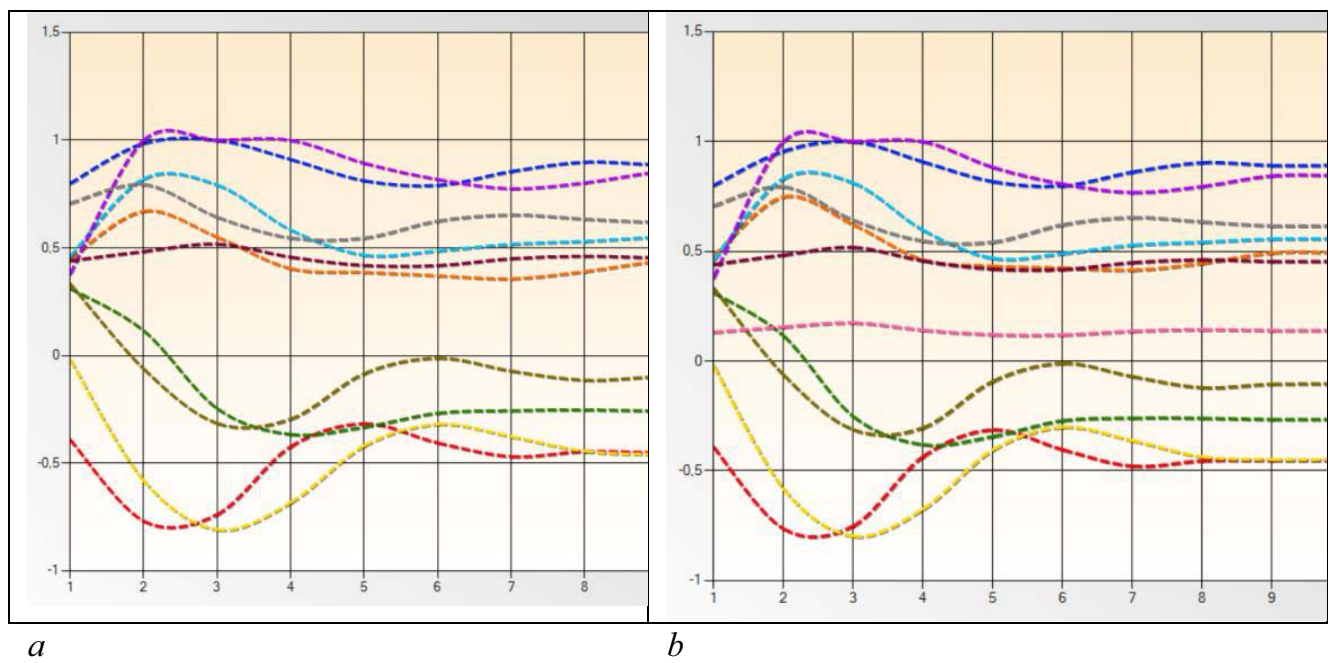

Fig. 7. Comparison of the dynamics of the evolution of the simulated FCM indicators when accounting for food exports

Consequently, the study of the agro-food system conducted by the method of fuzzy cognitive modeling on the example of the Volgograd region revealed the need to take into account, as well as add a control effect, to the top of the "Export" FCM graph of the simulated system.

\section{Conclusions}

The conducted cognitive modeling of the FS level in the conditions of forced import substitution showed that, although import substitution increases infrastructure costs associated with the provision of subsidies and tax benefits to enterprises engaged in the production and processing of food, it has a positive effect on the overall economic situation, as it determines the development of production. Import substitution in modern Russia ensures not only the achievement of the FS level required by the current Doctrine, but also ensures economic growth and, consequently, increased competitiveness.

The study of the mutual influence of the import substitution factor, within the framework of ensuring the required level of FS, is limited by the current prevailing conditions, largely determined by the sanctions pressure on the Russian Federation. The significance of the results obtained may decrease over time, and the possibilities and effectiveness of implementing the import substitution policy may decrease.

In connection with the above, a promising direction for conducting research to assess and ensure the required level of FS is to analyze the sensitivity of the cognitive model to the influence of all key factors and their impact on the level of FS, as well as to search for the most responsive to management actions on the part of management bodies for effective food security.

\section{Acknowledgements}

The article was prepared with the financial support of RFBR under the project 19-07-

01132 . 


\section{References}

1. E. Antamoshkinaet, Proceedings of the Volgograd State University International Scientific Conference "Competitive, Sustainable and Safe Development of the Regional Economy" (CSSDRE 2019) (2019)

2. N. Bannikovaet, Modern Applied Science, 9, 4 (2015)

3. J. Bernardes, Scripta Nova, 19 (2015)

4. V. Borisovet, Systems of Control, Communication and Security, 2 (2020)

5. K.Garthwaite, Social Science and Medicine, 132, 1 (2015)

6. P. Grouiez, Etudes Rurales, 190(2) (2012)

7. J. He, Marine Policy, 56, 1 (2015)

8. A. Jacknowitz, Children and Youth Services Review, 53(1) (2015)

9. C. Maitra, Source of the World Development, 72(1) (2015)

10. T. Mazaeva , Economy and entrepreneurship, 5(28) (2012)

11. K. Medernach, Etudes Rurales, 191(1) (2013)

12. A. Podvesovskii, International Journal of Open Information Technologies, 7(6) (2019)

13. S. Podgorskaya, Business Informatics, 13(3) (2019)

14. E.Popkova Asian social science, 11(20) (2015)

15. L. Popova, Mediterranean Journal of Social Sciences, 7(1), 1(2016)

16. N. Skiter, Mediterranean Journal of Social Sciences, 6(3,6) (2015)

17. N. Skiter, Applied Econometrics and International Development. Europe and Eurasia, 15(2) (2015)

18. A. Zagranovskaya, Bulletin of Plekhanov Russian University of Economics, 4(100) (2018) 